\title{
Control Strategy to Generate PWM Signals with Stability Analysis for Dual Input Power Converter System
}

\author{
J N Hemalatha ${ }^{1}$, S A Hariprsasad ${ }^{2}$, G S Anitha ${ }^{3}$ \\ ${ }^{1,3}$ EEE Department, Rashtreeya Vidyalaya College of Engineering $(\mathrm{R})$, Bengaluru, India \\ ${ }^{2}$ ECE Department, School of Engineering \& Technology, Jain University, Bengaluru, India
}

\begin{tabular}{l} 
Article Info \\
\hline Article history: \\
Received Jan 18, 2019 \\
Revised May 1, 2019 \\
Accepted Nov 27, 2019 \\
\hline Keyword: \\
Multiple Input Single output \\
(MISO) \\
Pulse Width Modulated (PWM) \\
hybrid power system \\
state space model \\
stability
\end{tabular}

\begin{abstract}
The prime role of a renewable resource-based DC hybrid power system is, to maintain the output voltage constant with higher efficiency. In order to achieve this the duty cycles of the converter switches are dynamically controlled. Multiple input single output (MISO) converter uses separate controller for adjusting the duty cycle, this complicates the design and implementation of the system. Hence, to overcome this limitation a centralized controller is used. The control strategy depends on the pattern of gating signals given to the converter switches. When independent controller is employed, then gating signals of any pattern can be used to drive the switches. However, if a single controller is used, and then a definite pattern is very much essential otherwise, the output voltage and efficiency get affected. In this paper, an attempt is made to validate and evaluate the performance parameters of MISO converter with two pattern of gating signals; they are synchronized and unsynchronized pulses at their rising edge. The control strategy focusses on the generation of these gating pulses. PID controller is tuned appropriately to determine the gains to achieve the stability of the proposed converter. The dual input power converter validated to show how the PWM pattern affects the efficiency, ripple and regulation of the converter. Using MATLAB SIMULINK platform, the simulation of the proposed concept with dual input converter in closed loop is validated. Simulation results proves that synchronized pulses gives DC efficiency of $87 \%$ at designed output of $12 \mathrm{~V}$ output. Converter with unsynchronized PWM pulses operates at lesser efficiency of $75 \%$ and the output voltage is of $10 \mathrm{~V}$.
\end{abstract}

Copyright $(0) 2018$ Institute of Advanced Engineering and Science. All rights reserved.

\section{Corresponding Author:}

Hemalatha J N,

EEE Department,

Rashtreeya Vidyalaya College of Engineering $(\mathrm{R})$,

Bengaluru, India,

Email: hemalathajn@rvce.edu.in

\section{INTRODUCTION}

One of the performance parameters of DC-DC converter is the regulation of output voltage.There are many techniques that are employed to control the output voltage of converters, but it is always in demand for many industrial applications to have a simple and low cost controller structure. Every control method has its own merits and demerits, the selection of a controller depends on various operating conditions. Commonly used control techniques are PWM Voltage-mode control and PWM Current-mode control. These control schemes have been widely used in low-voltage low-power switch-mode dc-dc converters [1]-[4]. Voltage mode technique uses single feedback loop, an error is produced by comparing the output voltage with reference voltage. The error voltage is compared with fixed frequency signal to generate PWM pulse that decide the switching duty ratio. The current mode controller is more complex than voltage mode controller. It is a double loop method, contains both voltage and current control loops. This technique essentially senses the inductor 
current to control the duty cycle. An error is obtained by comparing output voltage with a fixed reference voltage and utilized to produce control signal. However, the key advantages of current mode control are better phase compensation, feedback loop is more stable and load transient response is faster. The main limitation of these conventional control methods is that they fail to operate satisfactorily for large variation in parameters or load. Therefore, to overcome these limitations nonlinear controllers came into existence. They respond fastly for rapid changes in the operating parameters. Different types of nonlinear controllers are hysteresis controller, sliding mode controller etc [5]-[6].

In hysteresis control method, the output voltage ripple is detected, depending on this ripple value the duty ratio is controlled to regulate the output voltage. In this technique, directly the output voltage is monitored by using a comparator. The device is operated by simply checking whether the output voltage is fallen below or above a predefined threshold value. With this mechanism there are two control schemes they are, for a voltage set above the preset value or below the preset value. The response time is fast but variable switching frequencies is a serious problem and requires a output capacitor with high internal resistance.

In sliding mode control method, the control parameter track the desired path to meet the required point and operate at infinite switching frequency. But in practice it is not acceptable to work with an infinite switching frequency as it complicates the design of output filter. Also operating at very high switching frequency results in high conduction and switching losses and hence efficiency reduces. So DC- DC converters with SM controller, are designed to operate at a particular range of frequencies. In adaptive hysteresis band control method the variation happens within a band to control the required parameter and operates at fixed frequency. As the number of components required are more these methods are not preferred for low voltage applications [7]-[9]. The design complexity increases further with multiple input system as the order of the system is higher

Feedback loop techniques discussed above, automatically maintains a precise output voltage irrespective of changes in input voltage and variations in load conditions. The feedback control techniques are implemented with either proportional (P), proportional integral (PI), and proportional integral derivative (PID) types. The key parameters for the selection of controller are good stability, quick response, settling time should be less, less overshoot, simple in implementation and cost effective [10]-[12].

Generally in multi input hybrid systems, the duty cycle of the switching device controls the power delivered by each source. Dynamic control of the duty cycles is utmost important when a MISO system is designed to operate in transferring the power individually or simultaneously. The performance parameters like the output voltage and efficiency depends on the duty cycles. Therefore, it is very essential to have a proper control strategy for generating the PWM pulses. Conventionally, by using individual controllers for each converter or by using coupled inductors the output voltage is controlled. With these techniques, the converter is bulky, complex to design and implement due to increased component count. So to overcome these limitations, a centralised controller is used. The analysis, control and stabilization of switching converters are the main factors need to be addressed in the design of hybrid power system(HPS) with dynamic changes in duty cycle[13]-[19].

Whatever may be the controller technique used linear or nonlinear type, the gating pattern of the pulses generated by the controller is very important. [20] Proposes a control technique for dual input SEPIC converter with single PID controller. The control strategy employs two PWM generators to produce two gating pulses that are out of phase to regulate the output voltage. This technique is simple in implementation and the results shows that the output voltage is regulated at $12 \mathrm{~V}$ but then, the proposed strategy transfers power to load independently but fails to transfer simultaneously.

To address this issue, in this paper conventional PID controller in voltage control mode is chosen for dual input SEPIC converter with synchronized and unsynchronized gating pulses. The proposed technique in addition with regulation of output voltage it has the ability to transfer power individually or simultaneously. MATLAB Simulink is used to validate and compare the performance parameters of the converter. Stability analysis performed by tuning the controller properly, so that the system is stable with allowable gain margin and phase margin of the system.

The organization of the paper is as follows section 2 describes the stability analysis of the converter. Section 3 explains the validation of the performance analysis of the dual input modified SEPIC topology with and without the synchronized gating pulses, Section 4 discuss the conclusion and future scope.

\section{STABILITY ANALYSIS OF THE SYSTEM}

Generally, P controller simply multiplies an error by the proportional gain. It gives faster response but increase in $\mathrm{Kp}$, increases the overshoot. It is very difficult to get zero steady state error and good transient response using only proportional control. So to improve the system performance, to get steady state error zero and to have better response, an Integral or derivative controller should be included in the system. The integral term accelerates the movement of the process towards set point and responds to accumulated errors from the 
past. Derivative term slows the rate of change of the controller output, reduce the magnitude of the overshoot and improve stability. It is highly sensitive to noise and hence with the stability of the system. PD controller decrease the system settling time considerably but increase the bandwidth. The output must be equal to the set point; else, the error signal will not be zero. The signals (P, I and D) are assumed together to get output signal that will be made equal to set point. The controller is to be tuned in such a way that the system operates at stable condition. The stability analysis of SEPIC in series and parallel connection are discussed [19]. One of the technique to perform the stability analysis is by developing the small signal model of the proposed system. The performance Specifications like marginal stability, Transient response and bandwidth are upgraded utilizing tuning of PID controller. MATLAB online tuning tool used to get the controller gains. The block diagram to obtain the small signal model with two control parameters is as shown in the Figure 1.

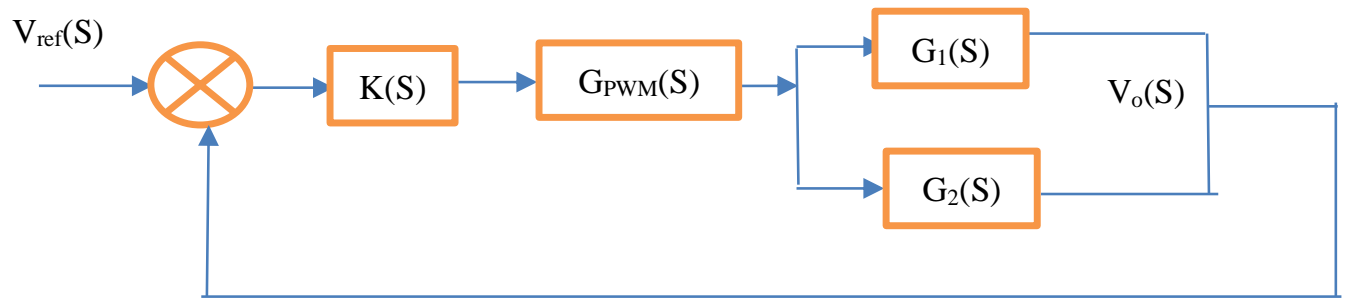

Figure 1. Closed loop controller of the hybrid system

The effective transfer function $\mathrm{G}(\mathrm{s})$ of the system is given by equation (1)

$\mathrm{G}(\mathrm{s})=\mathrm{k}(\mathrm{s}) \mathrm{G}_{\mathrm{pwm}}(\mathrm{s})\left[\mathrm{G}_{1}(\mathrm{~s})+\mathrm{G}_{2}(\mathrm{~s})\right]$

The loop gain expression of the system is given by equation (2)

$\frac{\mathrm{Vo}(\mathrm{S})}{\operatorname{Vref}(\mathrm{S})}=\frac{\mathrm{G}(\mathrm{S})}{1+\mathrm{G}(\mathrm{S})}$

Stability analysis is very much essential to fix the gains of the controller. With a PID control, the regulation of the output is possible if and only if $\mathbf{G}(s) \mathrm{H}(\mathrm{S})$ in open loop is stable. To design the gains of PID it is required to obtain the transfer function of the system.

To obtain the linearized model of DISEPIC conventional small-signal modelling approach is considered. If the control inputs in the small signal model are the duty cycles deviations for both input switches, then it is possible to choose two out of the following four input-output pairs: $\left(\mathrm{K}_{1}, \mathrm{Vo}\right),\left(\mathrm{K}_{2}, \mathrm{~V}_{\mathrm{o}}\right)$ and $\left(\mathrm{K}_{2}, \mathrm{I}_{\mathrm{L} 2}\right)$ or $\left(\mathrm{K}_{1}, \mathrm{I}_{\mathrm{L} 1}\right)$. However, physical insight suggests that the loop should be based on the pairs $\left(\mathrm{K}_{1}\right.$, Vout) and ( $\mathrm{K}_{2}$, $\left.\mathrm{V}_{\text {out }}\right)$, while the effects of $\left(\mathrm{K}_{2}, \mathrm{I}_{\mathrm{L} 2}\right),\left(\mathrm{K}_{1}, \mathrm{I}_{\mathrm{L} 1}\right)$ are to be considered as disturbances between loops.

Consider that the state variables $x_{i}(\mathrm{t})$, their steady state equilibrium values $X_{i}$ and their respective perturbed values $\tilde{x}_{l}$. The expression of state variable equation related by equation (3).

$x_{i}(\mathrm{t})=X_{i}+\tilde{x_{l}}$

The duty cycles $\mathrm{k}_{\mathrm{i}}(\mathrm{t})$ constitutes the input control signals. They are related with their respective constant value at the equilibrium point $\mathrm{K}_{i}$ and perturbed duty cycle $\mathrm{K}_{\mathrm{i}}(\mathrm{t})$ and given by equation (4).

$K_{i}(\mathrm{t})=K_{i}+\widetilde{k}_{l}$

The dynamic equations of the dual input SEPIC [21] in matrix form is expressed as

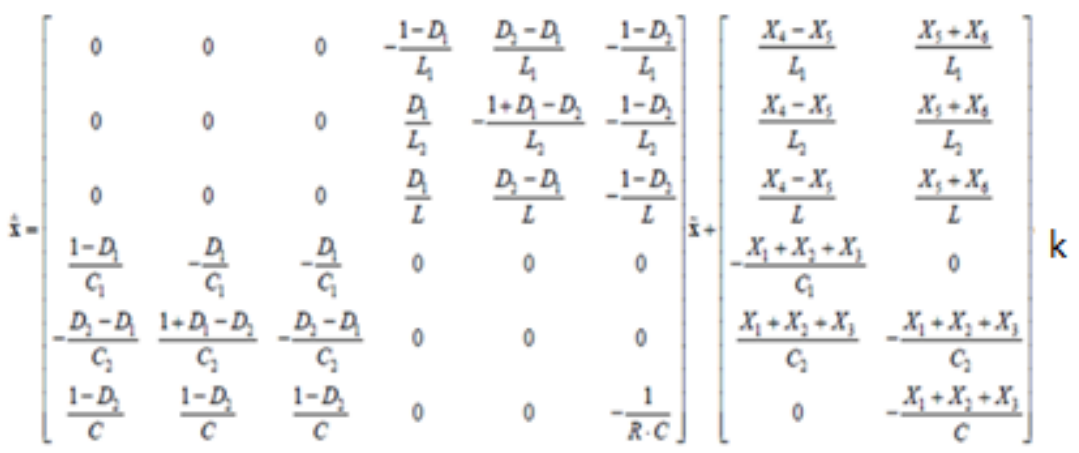

The expression for the output voltage is given by the equation (5)

$\mathrm{Y}^{\prime}=\left[\begin{array}{llllll}0 & 0 & 0 & 0 & 0 & 1\end{array}\right] \mathrm{x}+[0] \mathrm{k}$

Control Strategy to Generate PWM Signals with Stability Analysis ... (JN Hemalatha et al) 


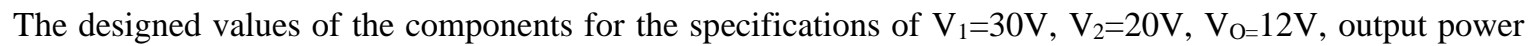
$100 \mathrm{~W}$, switching frequency $150 \mathrm{KHz}$ are estimated as given in [21] are listed below.

$\mathrm{L}_{11}=\mathrm{L}_{21}=1.25 \mathrm{mH}, \mathrm{C}_{11}=\mathrm{C}_{21}=66 \mu \mathrm{F}, \mathrm{L}=0.125 \mathrm{mH}, \mathrm{C}=100 \mu \mathrm{F}, \mathrm{R}=4 \Omega$

The state matrix representation of the equations is given below

$\dot{x}=\mathrm{A} \tilde{x}+\mathrm{B} \tilde{k}$

$\tilde{y}=\mathrm{C} \tilde{x}+\mathrm{K} \tilde{k}$

Since D is a zero-matrix, then the open loop control-to-output transfer function matrix of the converter is obtained by equation given in (6)

$$
\mathrm{G}(\mathrm{s})=\mathrm{C}(\mathrm{sI}-\mathrm{A})^{-1} \mathrm{~B}
$$

After substitution $\mathrm{C}(\mathrm{sI}-\mathrm{A})^{-1}$ is given by

$$
G(S)=\left(\begin{array}{llllll}
0 & 0 & 0 & 0 & 0 & 1
\end{array}\right) \cdot\left(\begin{array}{cccccc}
s & 0 & 0 & 350 & -150 & 200 \\
0 & s & 0 & -150 & 350 & 250 \\
0 & 0 & s & -2500 & -1667 & 4167 \\
-8750 & 3750 & 3750 & s & 0 & 0 \\
2500 & -10000 & -2500 & 0 & s & 0 \\
-8333 & -8333 & -8333 & 0 & 0 & s+3333
\end{array}\right)^{-1}
$$

To determine the transfer function, code is written in MATLAB. The Bode plot and step response plot obtained are as shown in Figure 2 and Figure 3 respectively.

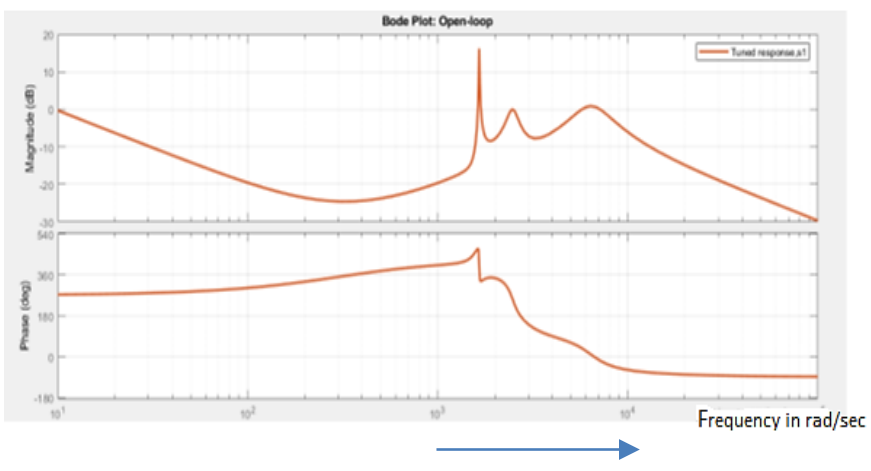

Figure 2. Bode plot of System

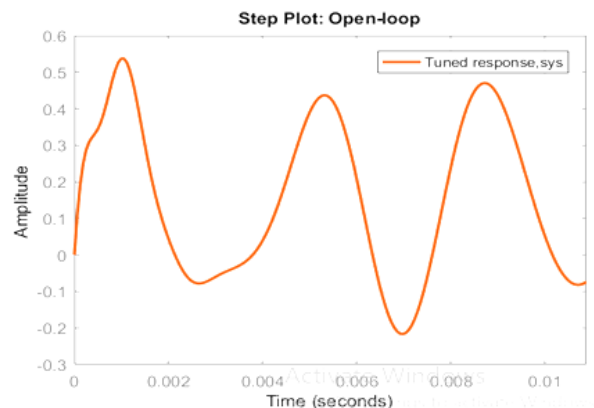

Figure 3. Step response of the system

The tuned values of $\mathrm{Kp}, \mathrm{Ki}$ and $\mathrm{Kd}$ with the time response parameters of the controller that results in stable system with allowable gain and phase margin is as shown in Figure 4, Tf indicates the Time constant of the first-order derivative filter. It can be:

- A real, finite, and nonnegative value.

- An array of real, finite, and nonnegative values.

- A tunable parameter (realp) or generalized matrix (genmat).

- A tunable surface for gain-scheduled tuning created using tunable Surface. (Source: https://in.mathworks.com/help/control/ref/pid.html) 


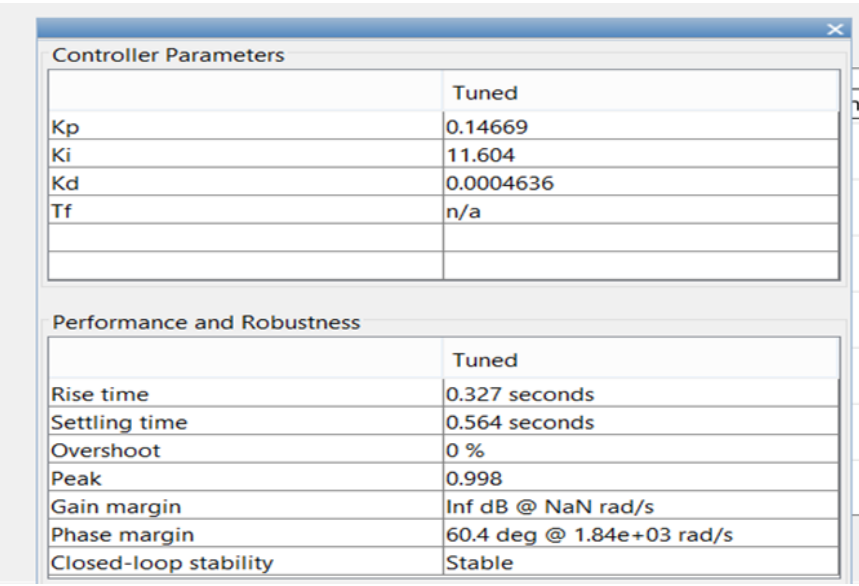

Figure 4. Controller parameters

\section{PERFORMANCE EVALUATION OF PROPOSED SYSTEM IN CLOSED LOOP}

Generally, in multi input HPS separate controllers are used for every source to regulate the DC bus voltage with random gating pattern. In single controller technique, one of the duty cycle is fixed and the other was varied to regulate the output voltage. Both the mechanism are not very effective for all conditions.

In this paper a centralized controller is designed that has two control parameters to regulate the output voltage. The block diagram of the dual input converter in closed loop system with controller is shown in Figure 5. $\mathrm{VG}_{1}$ and $\mathrm{VG}_{2}$ are the pulses given to the devices in the converter. With independent controllers for each converter, there is no restriction on the pattern of gate pulse but with single controller, the pulses are time shared with same switching frequency. The power circuit of DISEPIC is as shown in Figure 6 and the desired gating pattern is as shown in Figure 7.

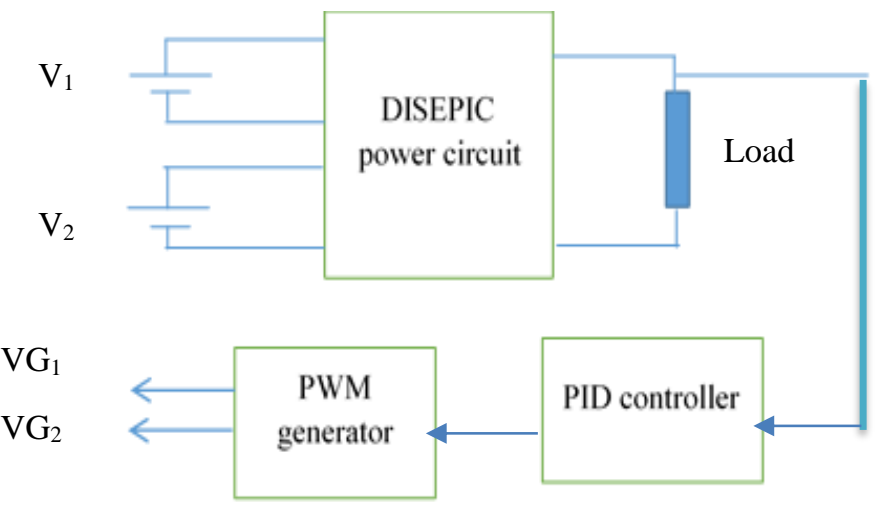

Figure 5. Complete block diagram of the proposed converter in closed loop

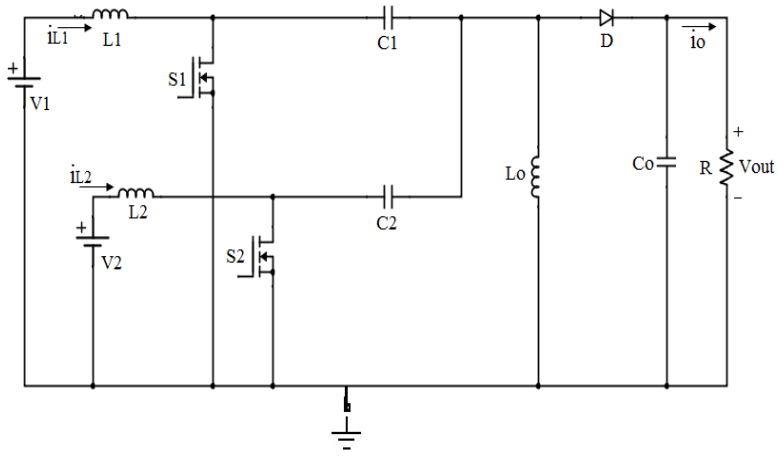

Figure 6. Power circuit of DISEPIC

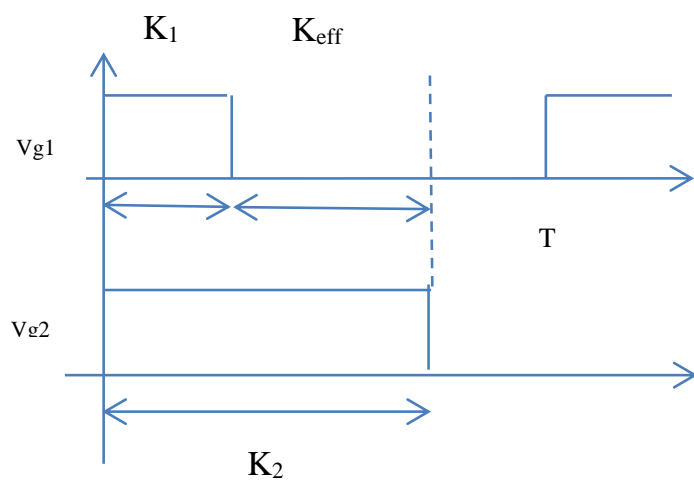

Figure 7. Gating pattern 
The output voltage expression $\mathrm{V}_{\text {out }}$ as indicated in Figure 2 of DISEPIC [21] is given by equation (7):

$\mathrm{V}_{\mathrm{out}}=\frac{\mathrm{V} 1(\mathrm{~K} 1)+\mathrm{V} 2(\mathrm{~K} 2-\mathrm{K} 1)}{(1-\mathrm{K} 2)}$

Where $K_{1}$ is the duty ratio of switch 1 and $K_{2}$ is the duty ratio of switch $2, K_{\text {eff }}=K_{2}-K_{1}$.

The expression for the output power $\mathrm{P}_{\mathrm{o}}$ is :

$\mathrm{P}_{\mathrm{o}}=\mathrm{V}_{\mathrm{o}}^{2} / \mathrm{R}_{\mathrm{L}}$

Efficiency $=\mathrm{P}_{\text {out }} / \mathrm{P}_{\text {in }}$

Equations (7) - (9) clearly shows that the output voltage as well as output power are functions of duty cycle. If any changes in the duty ratio affects the efficiency and the average output voltage. So to validate this the proposed system is simulated in MATLAB with different gating patterns.

The Simulink diagram of proposed converter with independent controllers is as shown in Figure 8. The blown-up view of controller is as shown in Figure 9. The performance parameters are evaluated to test the effect of un-synchronization of PWM pulses at rising edge.

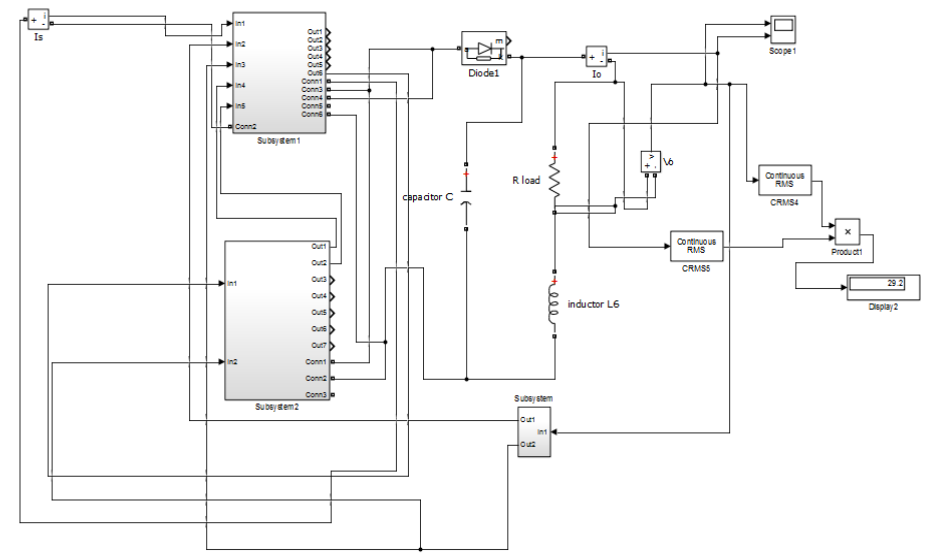

Figure 8. Simulink diagram of proposed system in closed loop

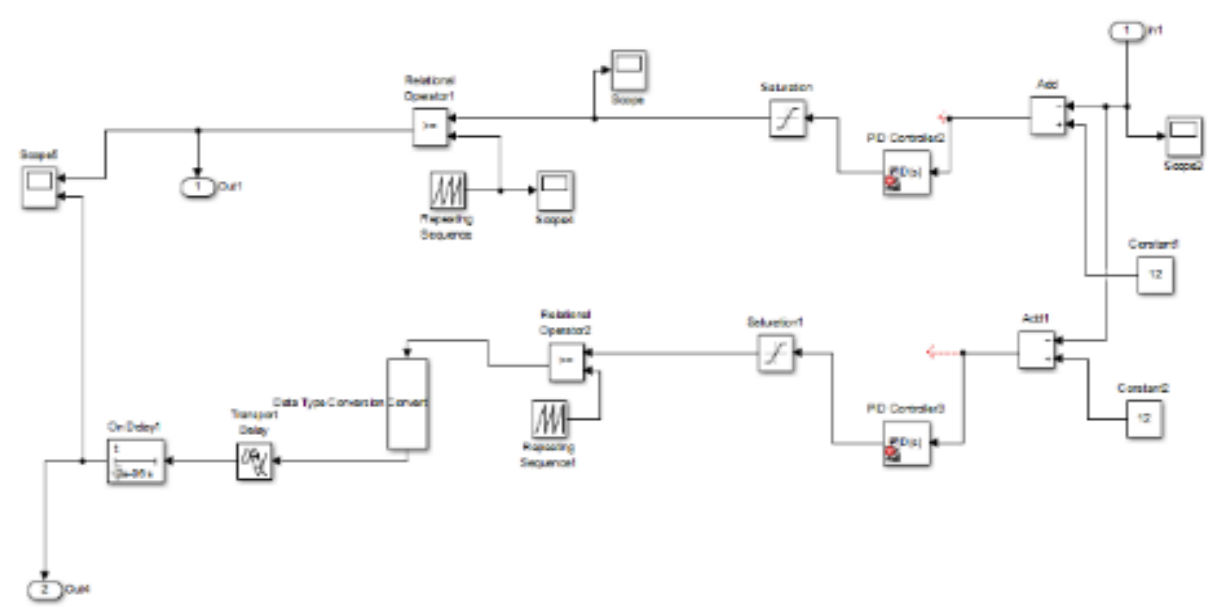

Figure 9. Blown up view of controller subsystem with independent controllers 


\subsection{With unsynchronised PWM pulses}

A delay in the gate pulse introduced in PWM for the switching device of second stage. The waveform of the gating pulses is as shown in Figure 10. The waveforms of the output voltage and output current is as shown in Figure 11.

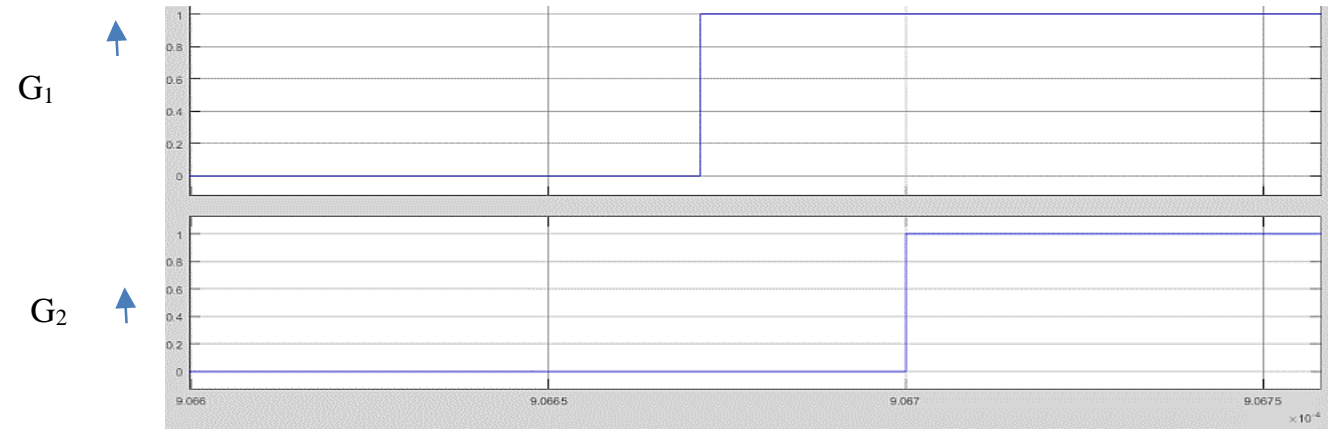

Time in secs

Figure 10. Gating signals

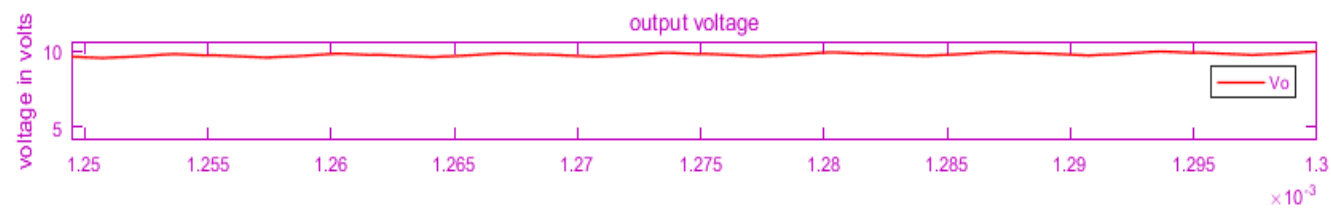

output current

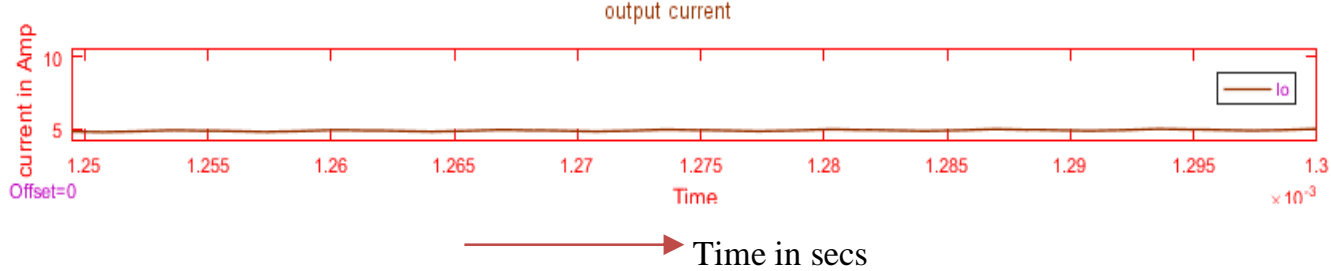

Figure 11. Waveforms of load voltage and load current

The performance parameters are listed in table 1. From the table it shows that the efficiency is $60.5 \%$ and output voltage is $9.5 \mathrm{~V}$ whereas the converter is designed for $12 \mathrm{~V}$.

Table 1. Performance parameters list

\begin{tabular}{lllll}
\hline $\mathrm{P}_{\text {in }}$ in watts & $\mathrm{P}_{\text {out }}$ in watts & Efficiency in $\%$ & $\mathrm{~V}_{\mathrm{o}}$ in volts & $\mathrm{I}_{\mathrm{o}}$ in amps \\
\hline 56.42 & 34.13 & 60.5 & 9.5 & 4.5 \\
\hline
\end{tabular}

\subsection{With synchronised PWM pulses}

The controller with synchronized pulses developed in SIMULINK is as shown in Figure 12. PWM pulses generated to the switching devices is as shown in Figure 13. The Figure 14 shows the waveforms of output voltage and output current respectively.
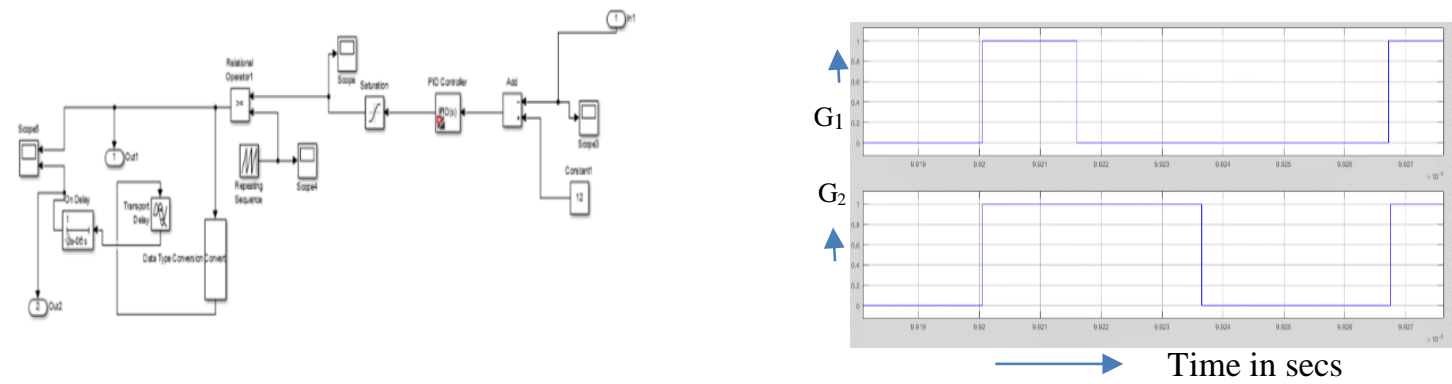

Figure 12. Controller with synchronized pulses.

Figure 13. Synchronized Gating pulses 
Table 2. Performance parameters
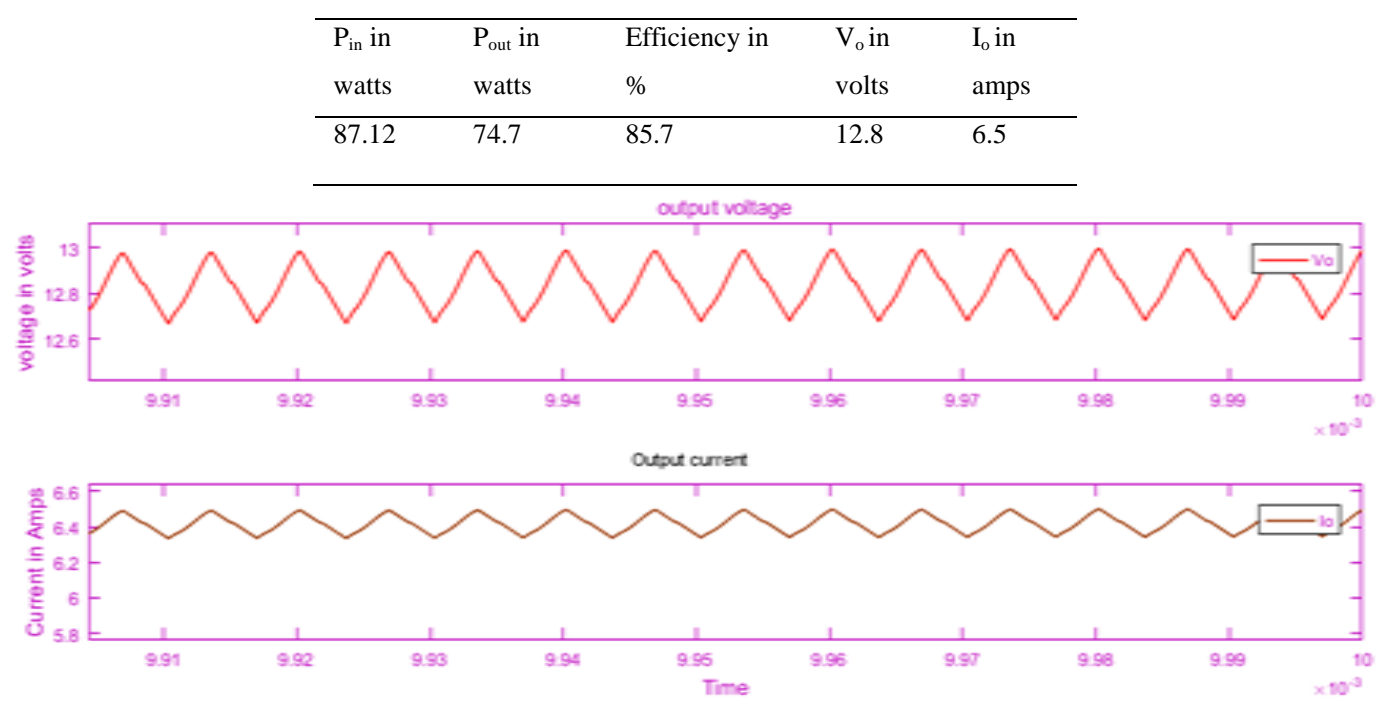

Time in secs

Figure 14. Waveform of voltage and current

The performance parameters tabulated as given in Table 2 . The results shows that the synchronised pulses improves the efficiency and output voltage is as per the designed value of $12 \mathrm{~V}$.

\subsection{Validation with variation in inputs}

As an extension, the proposed topology is validated for variations in input and load. The waveforms of the output current and output voltage are as shown in Figure 15. Figure 16 shows the source one and source two current. The parameters are tabulated as given in Table 3.
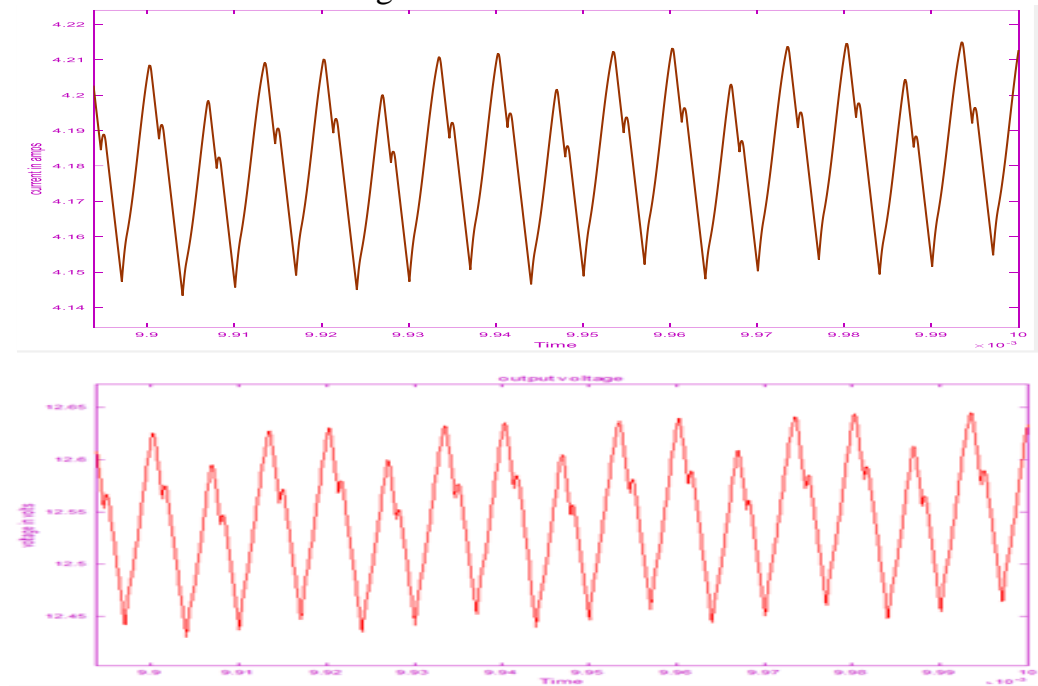

Figure 15. Waveforms of load voltage, load current

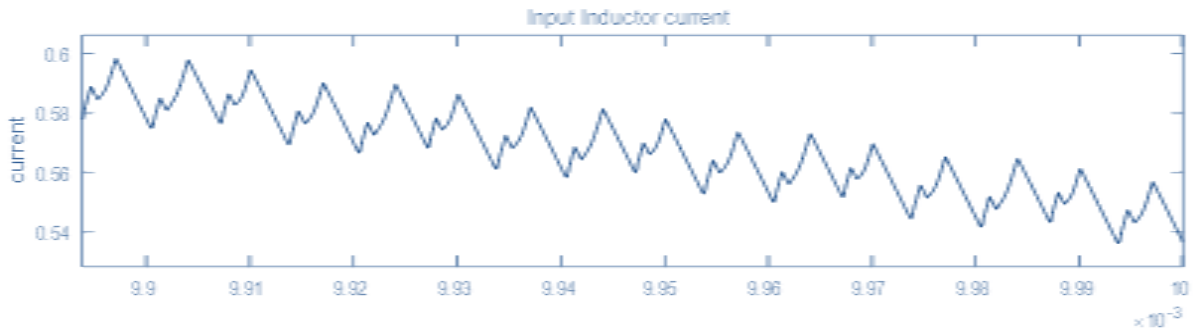




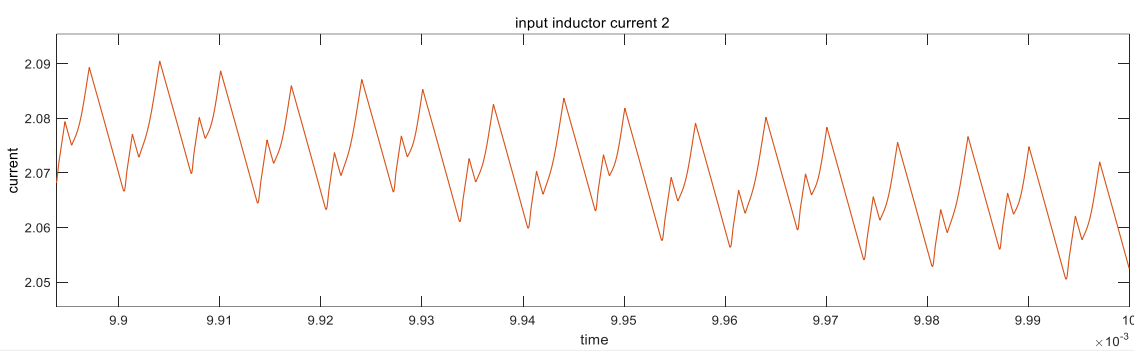

Figure 16 Source one current, source two current

Table 3. List of performance parameters

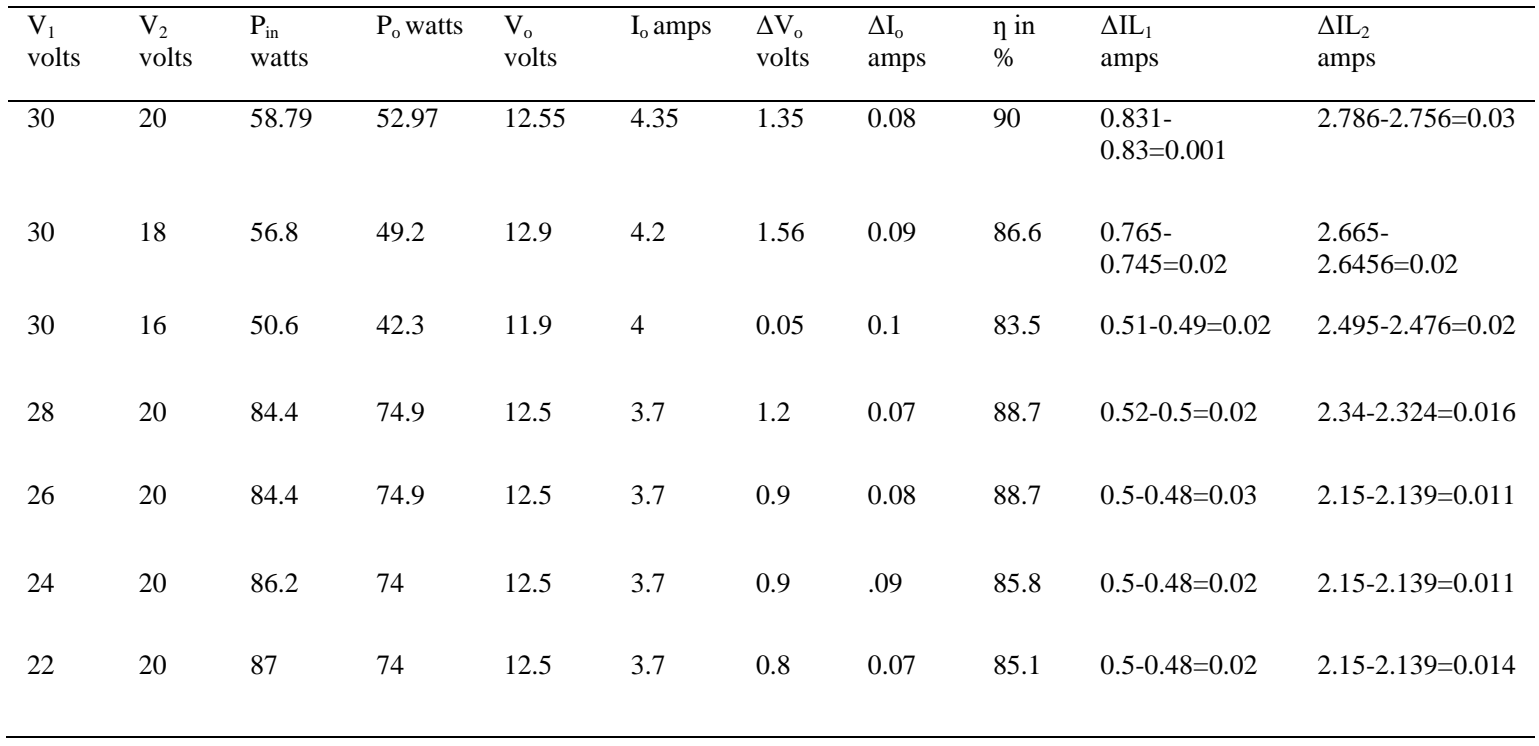

Table.4. Performance parameters with inductive load

\begin{tabular}{|c|c|c|c|c|c|c|c|c|c|c|}
\hline $\begin{array}{l}\mathrm{V}_{1} \\
\text { volts }\end{array}$ & $\begin{array}{l}\mathrm{V}_{2} \\
\text { volts }\end{array}$ & $\begin{array}{l}\mathrm{P}_{\text {in }} \\
\text { watts }\end{array}$ & $\mathrm{P}_{\mathrm{o}}$ watts & $\begin{array}{l}\mathrm{V}_{\mathrm{o}} \\
\text { volts }\end{array}$ & $\mathrm{I}_{\mathrm{o}} \mathrm{amps}$ & $\Delta \mathrm{V}_{\mathrm{o}}$ volts & $\begin{array}{l}\Delta \mathrm{I}_{\mathrm{o}} \\
\mathrm{amps}\end{array}$ & $\eta$ in $\%$ & $\begin{array}{l}\Delta \mathrm{IL}_{1} \\
\mathrm{amps}\end{array}$ & $\begin{array}{l}\Delta \mathrm{IL}_{2} \\
\mathrm{amps}\end{array}$ \\
\hline 75.29 & 61.43 & 81.5 & 11.6 & 5.834 & $\begin{array}{l}11.67- \\
11.66=0.01\end{array}$ & $\begin{array}{l}5.836- \\
5.833=0.003\end{array}$ & 0.82 & $\begin{array}{l}0.831- \\
0.83=0.001\end{array}$ & 2.775 & $\begin{array}{l}2.786- \\
2.756=0.03\end{array}$ \\
\hline 69.24 & 55.24 & 79.7 & 11.1405 & 5.571 & $\begin{array}{l}11.141- \\
11.1405=0.005\end{array}$ & $\begin{array}{l}5.7505- \\
5.7502=0.0003\end{array}$ & 0.75 & $\begin{array}{l}0.765- \\
0.745=0.02\end{array}$ & 2.86 & $\begin{array}{l}2.665- \\
2.6456=0.02\end{array}$ \\
\hline 50.46 & 41.89 & 83 & 11.82 & 3.945 & $\begin{array}{l}11.84- \\
11.83=0.01\end{array}$ & $\begin{array}{l}3.946- \\
3.944=0.002\end{array}$ & 0.51 & $\begin{array}{l}0.52- \\
0.5=0.02\end{array}$ & 2.33 & $\begin{array}{l}2.34- \\
2.324=0.02\end{array}$ \\
\hline
\end{tabular}

The proposed topology also validated for an inductive load. The waveforms of load voltage, load current is as shown in Figure 17. The waveforms of source one and source two current is as shown in Figure 18 and the results tabulated as given in Table 4.

From Table 3 and Table 4 it is shown that the converter works satisfactorily for variation in the source as the output voltage is regulated at $12 \mathrm{~V}$ and efficiency of the converter is above $82 \%$. 


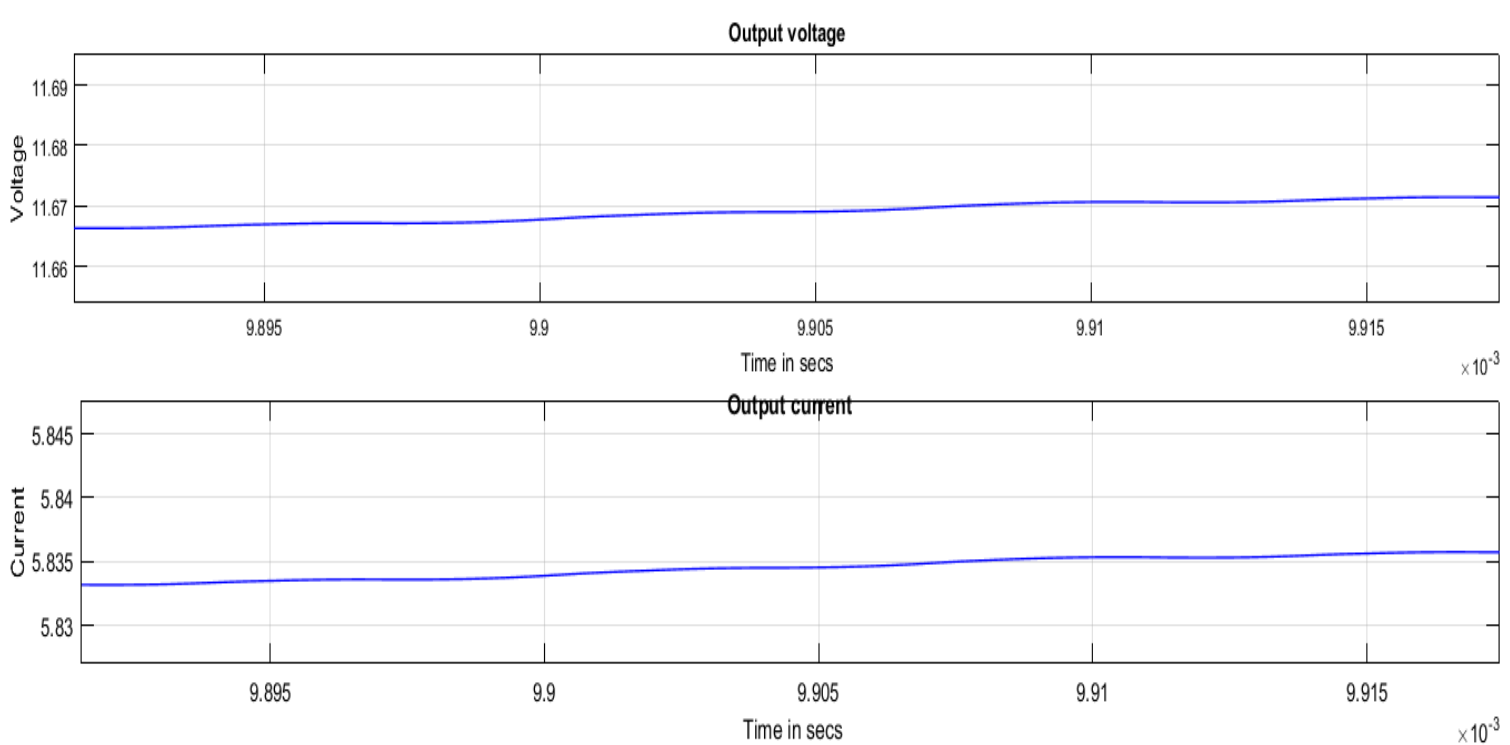

Figure 17.Waveforms of load voltage, load current
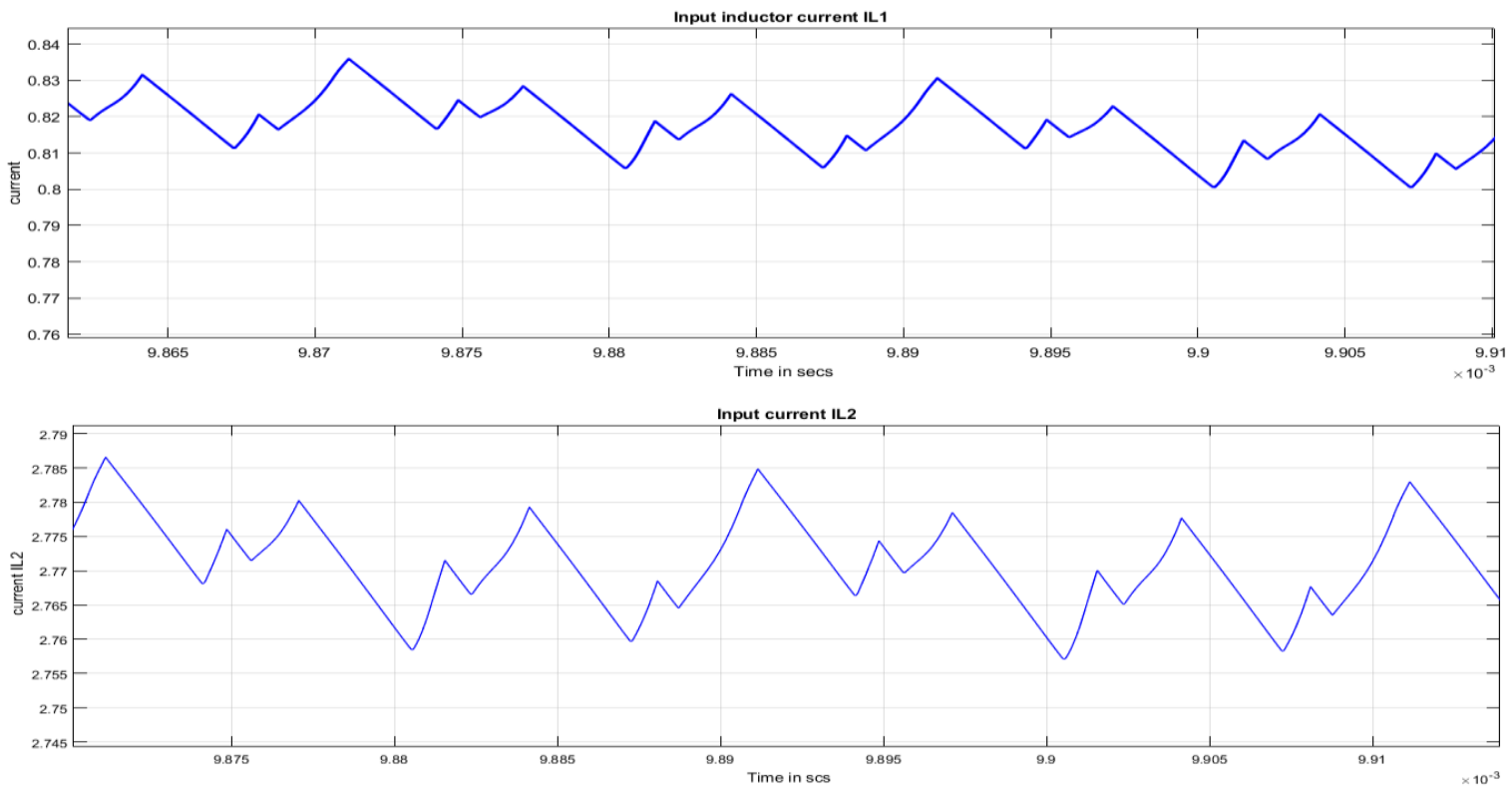

Figure 18. Waveforms of source one current, source two input current

\section{CONCLUSION}

In DC micro grids it is becoming essential to adopt multiple input converters (MICs) instead of many individual single input converters due to less complexity with reduced component count, cost and maintenance. The challenge is to regulate the output voltage by controlling the duty cycle of the converter switches. This paper discusses the design and development of centralised PID controller for controlling of output voltage with dual inputs rather than many controllers for every source. The validation of proposed dual input SEPIC converter with single controller in MATLAB/ Simulink platform with and without synchronization of PWM pulses is shown. In each case, the performance parameters like output voltage, efficiency and switching stress are tabulated. From the results, it is shown that when separate controllers are used and the gating pulses are not synchronised the efficiency reduces to $65 \%$ and output voltage, reduces to $10 \mathrm{~V}$ from designed value of $12 \mathrm{~V}$. Whereas with single controller where the gating pulses are synchronized efficiency is $85 \%$ and output voltage is $12 \mathrm{~V}$. In addition, the proposed control strategy tested for the converter under source variation and from the results, it is clear that the output voltage is constant at $12 \mathrm{~V}$; the DC efficiency is more than $85 \%$. 


\section{REFERENCES}

[1] Sujata Verma, S.K Singh and A.G. Rao, "Overview of control Techniques for DC-DC converters", Research Journal of Engineering Sciences, Vol. 2, pp 18-21, August 2013.

[2] Li-Jen Liu, et.all, "Analog PWM and Digital PWM Controller IC for DC/DC Converters", Fourth International Conference on Innovative Computing, Information and Control, 978-0-7695-3873-0/09, 2009.

[3] Mr.S.Dhanasekaran, et.al, "Different Methods of Control Mode in Switch Mode Power Supply- A Comparison", International Journal of Advanced Research in Electrical, Electronics and Instrumentation Engineering, Vol. 3, Issue 1, January 2014.

[4] M. Adonis and MTE Kahn, "Multiconverter controller design for an infrared heater grid", IEEE AFRICON , 978-14244-3919-5/09, September 2009,

[5] Waleed Ishaq Hameed 1, et.al, "Voltage Tracking Control of DC- DC Boost Converter Using Fuzzy Neural Network", International Journal of Power Electronics and Drive System (IJPEDS), Vol. 9, No. 4, December 2018, pp. 1657 1665.

[6] M. Khayamy, et al., "Adaptive Fuzzy Logic Control Mixing Strategy of DC/DC Converters in Both Discontinuous and Continuous Conduction Modes," Journal of Control, Automation and Electrical Systems, vol/issue: 27(3), pp. 274-288, 2016.

[7] He Y. and Luo F.L., "Sliding-mode control for dc-dc converters with constant switching frequency, Control Theory and Applications", IEEE Proceedings, 153, 37-45 (2006).

[8] K. Sujitha, et.al, "Performance Analysis of a Non Linear Process Using Different PID Control Techniques", International Journal of Advanced Research in Electrical, Electronics and Instrumentation Engineering", Vol. 3, Issue 9, September 2014.

[9] A. B. Muljono and I. M. Ginarsa, "Coordination of Adaptive Neuro Fuzzy Inference System (ANFIS) and Type-2 Fuzzy Logic System-Power System Stabilizer (T2FLS-PSS) to Improve a Large-scale Power System Stability," International Journal of Electrical and Computer Engineering (IJECE), vol/issue: 8(1), 2018.

[10] Chimaobi N. Onwuchekwa, and Alexis Kwasinski, "A Modified-Time-Sharing Switching Technique for MultipleInput DC-DC Converters" IEEE transactions on Power Electronics, vol. 27, no. 11, pp. 4492 - 4502, Nov 2012.

[11] O. Ibrahim and N. Z. Yahaya, "PID Controller Response to Set-Point Change in DC-DC Converter Control," International Journal of Power Electronics and Drive System (IJPEDS), vol/issue: 7(2), 2016.t

[12] P. V. R. Kumar and M. S. Kalavathi, "Fractional Order PID Controlled Interleaved Boost converter Fed Shunt Active Filter System," International Journal of Power Electronics and Drive System, vol/issue: 9(1), 2018

[13] Nithya. K and M. Ramasamy, "Modeling of Multi-Input DC-DC Converter for Renewable Energy Sources", International Journal of Innovative Research in Science, Engineering and Technology, Rasipuram, Tamilnadu, India, vol. 3, no. 1, Feb 2014.

[14] Hamid Behjati and Ali Davoudi "Discrete-time Modeling of Multiple-input DC Energy Conversion Systems", IEEE Electric Ship Technologies Symposium (ESTS), Arlington, pp. 66-70, 2013.

[15] Venkatanarayanan Subramanian and SaravananManimaran, "Design of Parallel-Operated SEPIC Converters Using Coupled Inductor for Load-Sharing", Journal of Power Electronics, Vol. 15, No. 2, pp. 327-337, March 2015

[16] M. Sai Krishna Reddy*, Ch. Kalyani, M. Uthra and D. Elangovan, "A Small Signal Analysis of DC-DC Boost Converter", Indian Journal of Science and Technology", Vol 8(S2), 1-6, January 2015.

[17] Arivukkannu Ezhilarasi and Muthiah Ramaswamy, "Stability Analysis of Series Connected SEPICs", IJCSI International Journal of Computer Science Issues, Vol. 9, Issue 6, No 2, November 2012

[18] D. Yang, M. Yang, and X. Ruan, "One-Cycle Control for a Double-Input DC/DC Converter," IEEE Transactions on power electronics, vol.27, no. 11, pp. 4646-4655, November 2012.

[19] N. Chimaobi, Onwuchekwa, and A.Kwasinski, "A Modified- Time-Sharing Switching Technique for Multiple- Input DC-DC Converters", IEEE transactions on power electronics, vol. 27, no. 11, pp. 4492-4502,November 2012.

[20] H. Y. Yong, N. I. Rusli and M. F. N. Tajuddin, "Output voltage control of dual input single ended primary inductor converter (SEPIC) for hybrid photovoltaic-piezoelectric system", 2017 IEEE Conference on Energy Conversion (CENCON), Kuala Lumpur, 2017, pp. 349-354

[21] Hemalatha J N, Hariprasad and Anitha G S, "Analysis and Evaluation of Performance Parameters of Modified Single Ended Primary Inductance Converter", International Journal of Power Electronics and Drive Systems (IJPEDS), Vol 8 , issue 4, pp 1585-1594, 2017 